\title{
Mhjournal
}

\section{El poder de la EXPERIENCIA}

Alba-María Martínez-Sala | albamaria.martinez@ua.es

Universidad de Alicante

El potencial de la EXPERIENCIA para despertar sentidos y emociones no es algo nuevo, no obstante, ha sido en las últimas décadas cuando ha ido cobrando protagonismo en disciplinas como el marketing, la comunicación, etc., por las posibilidades que ofrece a las organizaciones, sus marcas y sus productos y servicios para relacionarse y conectar con sus stakeholders estableciendo vínculos que van más allá de la razón.

Superado el marketing tradicional y con este la concepción del mercado como un entramado de meros intercambios de productos y servicios, Ph. Kotler, considerado por muchos el padre del marketing, aludía a principios de siglo a la necesidad de evolucionar hacia un enfoque basado en las relaciones. Las organizaciones debían ser capaces de establecer auténticas relaciones, construidas a partir de sentimientos y basadas en la confianza, con sus stakeholders. Así mismo, debían aceptar que sus marcas se construyen como resultado de estas relaciones y de otras, entre los propios stakeholders, cuando comparten sus EXPERIENCIAS con relación a las marcas.

Esta nueva concepción, otorgaba un papel protagonista a los stakeholders que se vio acrecentado con la llegada del modelo web 2.0, al multiplicar exponencialmente el alcance de sus relaciones. Bajo el reinado del modelo 2.0, el individuo se relaciona a golpe de clic con cientos, miles, incluso millones, de personas y el motivo principal, lo que impulsa estas interacciones es, fundamentalmente, el deseo de compartir sus EXPERIENCIAS. Las organizaciones y sus marcas deben desencadenar este deseo para beneficiarse de las ventajas de la conversión de los stakeholders en adprosumers, desde el punto de vista de la atracción y captación de nuevos potenciales consumidores.

Respecto de la necesidad de construir y consolidar estas relaciones, surge la EXPERIENCIA como la solución perfecta por su poder para cautivar, atraer, etc., a las personas a partir de una combinación perfecta de emoción y razón. Las experiencias, positivas o negativas, favorecen el establecimiento de un vínculo emocional y el recuerdo. Su generación responde a las expectativas de un nuevo individuo sobreinformado, crítico, y con un papel mucho más activo en las relaciones con las organizaciones, al tiempo que ávido de nuevas sensaciones y vivencias. 
En el momento actual, no hay sector que escape al poder de la EXPERIENCIA. Con los efectos de la globalización y de la homogeneización convive el deseo de vivir experiencias inolvidables, totalmente personalizadas, que rompan con la rutina y nos permitan diferenciarnos. Esto ha llevado a cambios transcendentales en la manera de concebir el marketing, la comunicación, la publicidad, las RR. PP, etc., pero también la gestión de empresas y organizaciones en sectores como el ocio (series de TV, cine, eventos, eventos 2.0, etc.), la política, el deporte, el turismo, etc.

En este monográfico, gracias a las notables aportaciones conseguidas, se ha logrado abordar en profundidad, y desde una amplia perspectiva, el potencial de la EXPERIENCIA. El conjunto de artículos recogidos bajo este paraguas engloba investigaciones diversas, que abarcan desde la industria de bienes de consumo hasta la cultural, pasando por un sector de gran interés: los medios de comunicación tanto offline como online, donde, además, se abordan otros ámbitos de investigación relevantes como son la ficción televisiva, los eventos deportivos, la comunicación política y otros de mayor controversia como la inmigración.

La aparente desconexión de los ámbitos descritos confirma el auge y el protagonismo de la EXPERIENCIA, más allá del marketing empresarial, aunque sin olvidarlo, tal y como se evidencia en algunos de los artículos que también comprende este monográfico. Precisamente, el de las autoras Z. Fabiola González Romo y Ch. Pallarés Segura, La experiencia Nespresso, el marketing sensorial aplicado al sector del cafée, se centra en este ámbito del marketing empresarial, donde las tendencias más actuales aluden a la experiencia como la herramienta óptima para lograr el tan anhelado vinculo emocional entre marcas y consumidores. Su análisis de la flagship store de la marca Nespresso, desde el punto de vista de las experiencias de los sentidos, confirma la eficacia del marketing experiencial.

La autora C. Sánchez Olmos, también en el ámbito empresarial, pero en el sector del ocio y de los eventos, nos traslada al mundo de la música. Su artículo, La producción de conciertos como estrategia de marketing experiencial. Estudio de caso de las propuestas Fnac, Vodafone, Coca-Cola, Pepe Jeans y Levi's, parte igualmente desde la perspectiva del marketing experiencial, al probar las ventajas que este tipo de eventos tienen para las marcas a la hora de generar experiencias con sus públicos y como, en consecuencia, se han convertido en un nuevo formato publicitario de gran eficacia frente a la publicidad tradicional. Sus resultados muestran las características de las experiencias derivadas de los eventos de música en directo y también rasgos, menos positivos, fundamentalmente, para los músicos que se plantea analizar en futuras investigaciones.

Con su artículo Análisis de la ficción televisiva española según la experiencia de guionistas profesionales. Un estudio cualitativo sobre cómo es la ficción nacional, M. Marcos Ramos nos traslada al sector del cine y la TV, concretamente al de la ficción nacional para determinar el poder que la experiencia de los propios guionistas ejerce en sus creaciones. Se aporta en este sentido una visión de la experiencia que la considera como la semilla, a partir de la que desarrollar productos y servicios que conecten con los públicos.

También al ámbito de los mass media se circunscribe el artículo de los autores C. MárquezDomínguez, D. Caridad Ruiz-Onofre y B. Patricio Moreno-Gudiño, Análisis de la agenda mediática en El Comercio, El Universo y El Telégrafo de Ecuador. El análisis cualitativo y cuantitativo de las publicaciones de los mencionados diarios ecuatorianos llevada a cabo por los autores, pone el énfasis en el protagonismo de los lectores y en la generación de espacios colaborativos desde los que estos mismos determinan, en gran medida, las agendas mediáticas. Este contexto tampoco escapa al poder de la experiencia, al ser uno de los desencadenantes principales de la conversión de los lectores en prosumer y/o adprosumer en estos espacios. La experiencia es necesaria para que haya colaboración. 
Adentrados en el ámbito de los mass media, y habiendo aludido a la TV y a la prensa, no incluir un artículo sobre la radio resultaría imperdonable. El de A. Niñoles Galvañ y C. OrtegaGiménez, Discurso del odio en radio: análisis de los editoriales de las cadenas COPE y SER tras la llegada del Aquarius a España, ha permitido evitarlo. Su investigación sobre un tema tan candente como lo es la inmigración, dota además al monográfico de una dimensión social que lo enriquece en gran medida. Sus resultados no son muy alentadores, pues evidencian un uso normalizado de un lenguaje excluyente que poco favorece la cohesión social. Su lectura ahonda en las consecuencias de las experiencias resultantes de la exposición de la sociedad a los mass media.

Por último, no se podía dar por concluido el capítulo de los medios de comunicación sin aludir a las redes sociales. En este sentido, los lectores encontrarán dos títulos de gran interés, uno centrado en el uso de estos canales por los usuarios y otro relativo a su uso por parte de organizaciones, concretamente de partidos políticos. En el primero, Memes e imaginarios sociales mexicanos en la Copa del Mundial de la FIFA 2018, sus autores, J. Bañuelos Capistrán y B. Pérez Restovic, recurren al estudio de caso para comprender los imaginarios sociales que construyen la identidad cultural mexicana en redes sociales y sitios web informativos, a partir del estudio de memes. Su estudio confirma que representan imaginarios sociales derivados de la identidad cultural mexicana, poniendo de manifiesto de nuevo el poder de la experiencia, en este caso, de la resultante de un tipo de vivencia, un evento deportivo, que despierta unos poderosos sentimientos: los patrióticos. Para finalizar, J. Gamir Ríos, nos traslada al ámbito de la política donde se corrobora la eficacia de la EXPERIENCIA, al constituir una de las bases para el éxito de las estrategias de comunicación política. Su artículo, El uso político de Twitter en la campaña de las Elecciones Locales de 2015 en la ciudad de Valencia, analiza la comunicación en Twitter de diferentes formaciones políticas durante unas elecciones. El autor concluye acerca de un uso instrumental de la mencionada red social, así como un escaso aprovechamiento de su potencial experiencial para generar una comunicación multidireccional y establecer nuevas relaciones.

Los artículos referidos, a los que los/las lectores/as pueden acceder en el presente monográfico, son un fiel reflejo de la necesidad de abrir nuevos marcos de reflexión y nuevos enfoques de investigación sobre la EXPERIENCIA y las posibilidades que ofrece, en un amplio campo de disciplinas y actividades. Esperamos que la lectura de los mismos les proporcione una auténtica EXPERIENCIA tan satisfactoria, o más, que la vivida al leerlos para escribir este prólogo, así como al escribirlo.

Para finalizar, debo mencionar y destacar el notable trabajo y constante interés de todo el equipo editorial de la revista Miguel Hernández Communication Journal, integrado por la Dra. Montserrat Jurado Martín, Dra. Begoña Ivars-Nicolás, Dra. Carmen María López Rico, y Dr. Francisco Julián Martínez Cano. Sin ellos, sin duda, la EXPERIENCIA hubiera sido otra. 
MHCJ nº 11 (1) | Año 2020 - Prólogo - Páginas 13 a 16 - mhjournal.org

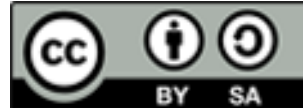

Licencia Creative Commons

Miguel Hernández Communication Journal

mhcj.es

\section{Cómo citar este texto:}

Alba-María Martínez-Sala (2020): "El poder de la EXPERIENCIA", en Miguel Hernández Communication Journal, nº11, páginas 13 a 16 Universidad Miguel Hernández, UMH (Elche-Alicante). DOI: http://dx.doi. org/10.21134/mhcj.v11i0.333 